УДК 616.89-008.441.33:159.9.018-055.52-055.2

Для цитирования: Краснятова Ю.А., Стоянова И.Я. Характеристики созависимости и психической саморегуляции у матерей подростков с наркотической зависимостью. Сибирский вестник психиатрии и наркологии. $2018 ; 1$ (98): $42-48$. https://doi.org/10.26617/1810-3111-2018-1(98)-42-48

\title{
Характеристики созависимости и психической саморегуляции у матерей подростков с наркотической зависимостью
}

\author{
Краснятова Ю.А. ${ }^{2}$, Стоянова И.Я. ${ }^{1,2}$ \\ ${ }^{1}$ Научно-исследовательский институт психического здоровья, Томский национальный исследовательский \\ медицинский центр Российской академии наук (НИИ психического здоровья Томский НИМЦ) \\ Россия, 634014, Томск, ул. Алеутская, 4 \\ ${ }^{2}$ Национальный исследовательский Томский государственный университет (НИ ТГУ) \\ Россия, 634050, Томск, пр. Ленина, 36
}

\section{PEЗЮME}

В статье рассматриваются особенности проявлений созависимости и психической саморегуляции и их взаимосвязи у матерей подростков с наркотической зависимостью (основная группа) в сравнении с матерями подростков без психических нарушений. Методы исследования: стандартизованное интервью, опросники созависимости Уайнхолда и В.И. Моросановой «Стиль саморегуляции поведения». Результаты исследования. Установлено, что высокая степень созависимости у матерей отмечается как в основной, так и контрольной группах (64,1\% и 53,3\%). Об-

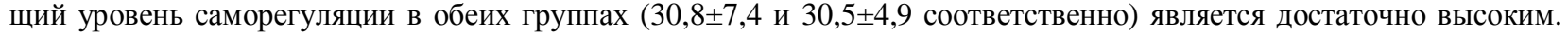
Взаимосвязь показателей индивидуально-стилевых особенностей саморегуляции и показателя созависимости в основной группе прослеживается по всем параметрам, кроме «Гибкости» и «Самостоятельности». Заключение. Показатели коэффициента вегетативного баланса свидетельствуют о наличии высокого уровня хронической психической истощаемости, которая является фактором риска нарушения психического здоровья. Программы психопрофилактики при созависимости должны включать направленность на снятие избыточного нервно-психического напряжения.

Ключевые слова: уровни созависимости, психическая саморегуляция, матери подростков с наркотической зависимостью.

\section{АКТУАЛЬНОСТЬ}

В настоящее время во всем мире увеличивается число людей, страдающих созависимостью. Проявления этого феномена являются важной проблемой в современном обществе, так как служат препятствием как для личностного роста, так и психического и социального здоровья [13]. Величина проблемы обусловливает и многоаспектность направлений исследования. Это связано с возрастающим числом пациентов с проявлениями зависимости и расширением числа семей, чьи представители страдают созависимостью $[14,15,17,18]$.

В других исследованиях рассматриваются вопросы нарушенных семейных отношений, которые способствуют формированию аддикции, обсуждаются возможности семейной превенции и психологической помощи представителям семьи с различным ролевым функционированием (матери, супруги) $[1,3,4,5,12,15,16]$.

Несмотря на различия в общеметодологических подходах, все практико-ориентированные и теоретические исследования семьи в контексте проблем наркозависимости опираются на два фундаментальных положения:

- семья играет важную роль, определяющую употребление наркотиков ее членами;

- $\quad$ отношения в семье оказывают влияние на психосоциальную реабилитацию наркозависимого.
В меньшей степени в научной литературе представлены направления, изучающие психологические факторы, обусловливающие психическое здоровье созависимых членов семьи [13].

При исследовании созависимости необходимо учитывать, что семейные условия с наличием зависимого от психоактивных веществ являются хронически стрессогенными, что существенно нарушает психическое здоровье членов семьи. Психологическое содержание созависимости можно представить с помощью следующих определений: 1) это искаженный стиль взаимодействия в семье [17]; 2) нарушенные отношения созависимых к себе, своей жизни, а также к зависимому родственнику [11, 19]; 3) неопределенность ценностей и смыслов [18]; 4) избыточные психологические защиты и неконструктивные стратегии совладания со стрессом [8].

Исследователи отмечают, что созависимость приводит к нарушениям на всех уровнях: физическом, эмоциональном, поведенческом, социальном и духовном [12]. Проведенные исследования свидетельствуют о необходимости дальнейших поисков эффективной психологической помощи с опорой на ресурсные составляющие психического здоровья у людей, страдающих созависимостью. В частности важным аспектом изучения созависимости в контексте психического здоровья являются проявления психической саморегуляции. 
Роль индивидуально-типологических особенностей осознанной саморегуляции в реализации личностных ресурсов человека занимает одно из центральных мест в общем контексте изучения человека [9]. При этом отсутствует психологическая информация о системном изучении особенностей психической саморегуляции, как о факторе психического здоровья у членов семьи с проблемами созависимости. Изучение взаимосвязи между проявлениями созависимости и особенностями психической саморегуляции позволит сформировать эффективные программы психологической помощи, направленные на сохранение психического здоровья.

Понятие психической саморегуляции рассматривается в качестве многоуровневой динамической системы, являющейся психологическим инструментом переработки информации для инициации, поддержания, контроля и коррекции активности, направленной на осознанное выдвижение и достижение субъектных целей [7, 9]. С помощью этой системы человек мобилизует и координирует свои психологические ресурсы для выдвижения и достижения целей своей активности. Критерием эффективности саморегуляции является ее осознанность.

При рассмотрении индивидуально-типических (стилевых) особенностей саморегуляции выделены 2 уровня: 1) индивидуальные проявления регуляторных процессов, реализующих основные звенья системы саморегулирования - планирование, моделирование, программирование и оценка результатов; 2) стилевые особенности, которые характеризуют функционирование всех звеньев системы саморегуляции и одновременно являются регуляторно-личностными свойствами (например, самостоятельность, надежность, гибкость, инициативность).

Интегральной характеристикой саморегуляции является общий уровень осознанной саморегуляции, которая отражает актуальные возможности человека по управлению произвольной активностью $[9,20]$.

Целью настоящего исследования является выявление характеристик созависимости и психической саморегуляции и определение их взаимосвязи у матерей пациентов с наркотической зависимостью.

\section{МАТЕРИАЛЫ И МЕТОДЫ}

Программа исследования включала стандартизованное интервью и валидизированные методы психодиагностики: опросник созависимости в модификации Уайнхолда [10] и модифицированной версии опросника В.И. Моросановой «Стиль саморегуляции поведения», позволяющего диагностировать степень развития осознанной саморегуляции и её индивидуальные профили, характеризующие устойчивость функционирования регуляторных процессов в условиях психической напряженности [9].

Статистическая обработка данных осуществлялась при использовании пакета стандартных программ Statistica for Windows (Ver. 12.0). Производились расчеты средней арифметической, стандартной девиации для установления количественных показателей.
Результаты представлены в виде среднего арифметического $\mathrm{M} \pm \mathrm{SD}$, где $\mathrm{M}$ - среднее арифметическое, SD - стандартное отклонение в случае нормального распределения. Соответствие нормальности распределения проводилось с использованием критерия Шапиро-Уилка.

В случае распределения, отличного от нормального, количественные данные представлены в виде медианы, нижнего и верхнего квартилей.

При обработке данных применялся метод tкритерия Стьюдента, с помощью которого анализировалась значимость различий двух групп по среднему значению какого-либо показателя. Критерий Стьюдента использовался для сравнения средних арифметических двух количественных признаков, имеющих нормальное распределение. Для каждой выборки вычисляли медиану, 25\% и 75\% квартили, статистическую значимость различий между группами определяли по критериям Манна-Уитни (для двух независимых выборок), Вилкосона (для двух зависимых выборок). Для сравнения групп по качественному признаку использовались таблицы сопряженности, критерий хи-квадрат Пирсона. Для анализа связи признаков использовался метод корреляционного анализа (непараметрический метод Спирмена).

Формируя выборку исследования, мы предполагали, что, во-первых, уровни созависимости будут более высокими в основной группе по сравнению с показателями контрольной группы. Во-вторых, что характеристики саморегуляции окажутся более эффективными у матерей с детьми без психических нарушений.

Выборка исследования включала две группы женщин (n=93), из них основную группу составили матери лиц подросткового возраста с наркотической зависимостью $(\mathrm{n}=54)$, в контрольную группу включены матери $(\mathrm{n}=39)$ подростков без психических нарушений. Средний возраст матерей основной группы - 53 года, контрольной группы - 48 лет. Средний возраст детей - 15 лет. Обе группы сопоставимы по образованию и составу семьи.

\section{РЕЗУЛЬТАТЫ И ОБСУЖДЕНИЕ}

Анализ стандартизованного интервью показал, что как в основной, так и в контрольной группе у матерей наркозависимых подростков в большинстве случаев отмечалась средняя удовлетворенность состоянием здоровья $(69,2 \%$ и $66,7 \%$, статистические различия незначимы).

Удовлетворенность семейными отношениями характеризуется следующими показателями. У матерей подростков с наркотической зависимостью преобладает средняя степень удовлетворенности $69,2 \%$, в контрольной группе этот показатель был значительно более низким - 20,0\%. При этом в контрольной группе в большей степени выражена высокая степень удовлетворенности отношениями членов семьи - 53,3\% против $28,2 \%$ в основной группе - $(\mathrm{p}>0,05)$. 
В качестве семейных проблем матери подростков обеих групп отмечают нарушенные взаимоотношения с детьми: в основной группе - $51,1 \%$, в контрольной группе - 53,3\% (различия незначимы). Второе место по значимости занимают материальные проблемы $-25,6 \%$ и $26,7 \%$ соответственно. На полное отсутствие семейных проблем указывают матери основной группы в $15,4 \%$ случаев, в контрольной - в 6,7\%.

Эти показатели, скорее всего, свидетельствуют о выраженности психологических защитных механизмов у матерей обеих групп. Следует обратить внимание и на некоторую разбалансированность показателей у матерей контрольной группы, у которых равнозначно представлены данные о высокой степени удовлетворенности семейными отношениями и наличии проблем во взаимоотношениях с детьми.

Проявления созависимости в выборке матерей обеих группп представлены в таблице 1.

Т а б и ц а 1

\begin{tabular}{|c|c|c|c|c|}
\hline \multicolumn{5}{|c|}{$\begin{array}{c}\text { Характеристики созависимости } \\
\text { в основной и контрольной группах }\end{array}$} \\
\hline \multirow{3}{*}{$\begin{array}{c}\text { Степень } \\
\text { созависимости }\end{array}$} & \multicolumn{4}{|c|}{ Выборка матерей подростков $(\mathrm{N}=93)$} \\
\hline & \multicolumn{2}{|c|}{$\begin{array}{c}\text { основная } \\
\text { группа }(\mathrm{n}=54)\end{array}$} & \multicolumn{2}{|c|}{$\begin{array}{c}\text { контрольная } \\
\text { группа }(\mathrm{n}=39)\end{array}$} \\
\hline & $\%$ & Абс. & $\%$ & Абс. \\
\hline 1 (очень высокая степень) & $12,8 *$ & 7 & $0 *$ & 0 \\
\hline 2 (высокая степень) & $64,1 *$ & 35 & $53,3 *$ & 21 \\
\hline 3 (средняя степень) & $20,5 *$ & 11 & $46,7 *$ & 18 \\
\hline 4 (низкая степень) & 2,6 & 1 & 0 & 0 \\
\hline
\end{tabular}

Методика определения уровня созависимости Уойнхолда позволяет выявлять 4 варианта этой характеристики. Результаты диагностики показали, что очень высокая степень созависимости выявлена у матерей основной группы. Высокая степень созависимости представлена значительным числом матерей как основной, так и контрольной группы с преобладанием матерей с наркозависимыми подростками. Средняя степень созависимости выявлена у пятой части основной группы и почти в половине случаев контрольной группы. Эти показатели свидетельствуют о значительных проявлениях созависимости как у матерей с наркозависимыми, так и у матерей, чьи дети не имеют проблем с ПАВ. При этом женщины контрольной группы также находятся в зоне риска, связанной с нарушениями личностного развития и психического здоровья, обусловленными уровнем созависимости.

Показатели психической саморегуляции произвольной активности у матерей обеих групп представлены в таблице 2 .

Анализ результатов психической саморегуляции произвольной активности матерей основной группы свидетельствует о том, что значения по шкале «Планирование» несколько превышают норму. Эти данные характеризуют сформированную потребность в осознанном планировании деятельности, реалистичности и устойчивости планов, самостоятельность при определении целей.
В контрольной группе отмечается снижение по шкале «Программирование», что свидетельствует о неумении матерей наркотизирующихся подростков продумывать последовательность своих действий, преобладании стиля «проб и ошибок».

Т а б ли ц а 2

\begin{tabular}{|c|c|c|c|}
\hline \multicolumn{4}{|c|}{$\begin{array}{c}\text { Психическая саморегуляция } \\
\text { в основной и контрольной группах }\end{array}$} \\
\hline \multirow[t]{2}{*}{ Шкала } & \multicolumn{2}{|c|}{$\begin{array}{c}\text { Выборка матерей подростков } \\
(\mathrm{N}=93\end{array}$} & \multirow{2}{*}{$\begin{array}{c}\text { Средняя } \\
\text { норма }\end{array}$} \\
\hline & $\begin{array}{c}\text { основная } \\
\text { группа }(\mathrm{n}=54)\end{array}$ & $\begin{array}{c}\text { контрольная } \\
\text { группа }(\mathrm{n}=39)\end{array}$ & \\
\hline Планирования & $6,2 \pm 1,8$ & $5,8 \pm 1,7$ & $4,9 \pm 1,9$ \\
\hline Моделирования & $5,2 \pm 2,0$ & $5,1 \pm 1,4$ & $5,3 \pm 1,8$ \\
\hline Программирования & $5,4 \pm 1,9$ & $4,9 \pm 1,6$ & $6 \pm 1,7$ \\
\hline Оценки результатов & $5,0 \pm 2,4$ & $5,4 \pm 1,5$ & $5,2 \pm 1,6$ \\
\hline Гибкости & $5,6 \pm 1,7$ & $5,7 \pm 2,3$ & $6,6 \pm 1,8$ \\
\hline Самостоятельности & $5,4 \pm 2,0$ & $5,3 \pm 2,2$ & $5,5 \pm 2$ \\
\hline Надежности & $3,9 \pm 2,4$ & $4,5 \pm 1,8$ & $5,5 \pm 1,8$ \\
\hline OYC & $30,8 \pm 7,4$ & $30,5 \pm 4,9$ & $28,3 \pm 4,9$ \\
\hline
\end{tabular}

По шкале «Надежность» отмечаются низкие показатели у матерей основной группы. Это свидетельствует о сложностях продумывания действий и поведения для достижения намеченных целей, отсутствия возможностей в адекватной оценке результата своей деятельности. Выражено рассогласование промежуточных результатов в ситуации повышенной и заниженной мотивации деятельности, высокой и низкой психической напряженности.

Таким образом, в целом выявлен достаточный общий уровень саморегуляции как в основной, так и в контрольной группах. При этом имеются рассогласования между отдельными звеньями саморегуляции. Данные противоречия, по всей вероятности, связаны с повышенным уровнем нервно-психической напряженности у матерей обеих групп. Эти данные необходимо проверить в дополнительных исследованиях.

С целью выявления взаимосвязи между созависимостью и индивидуально-стилевыми особенностями саморегуляции, характеризующими основную группу, проведен корреляционный анализ количественных переменных по Спирмену. При корреляционном анализе значимы два показателя - коэффициент взаимосвязи $\left(\mathrm{r}_{\mathrm{s}}\right)$ и коэффициент достоверности взаимосвязи (p).

Корреляционный анализ выявил следующие особенности, характеризующие матерей подростков, зависимых от ПАВ. Взаимосвязь показателей индивидуально-стилевых особенностей саморегуляции и степени созависимости в основной группе прослеживается по всем шкалам, кроме «Гибкости» и «Самостоятельности». Установлена взаимосвязь между показателями планирования и степенью созависимости (рис.1).

У матерей с очень высокой степенью созависимости показатель по шкале «Планирование» $4,4 \pm 1,7$ статистически значимо отличается от показателя второй и третьей степеней созависимости (2-я

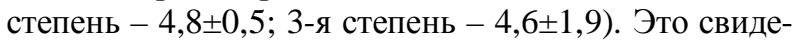
тельствует о сниженной саморегуляции по сравнению с высокой и средней степенями созависимости. 


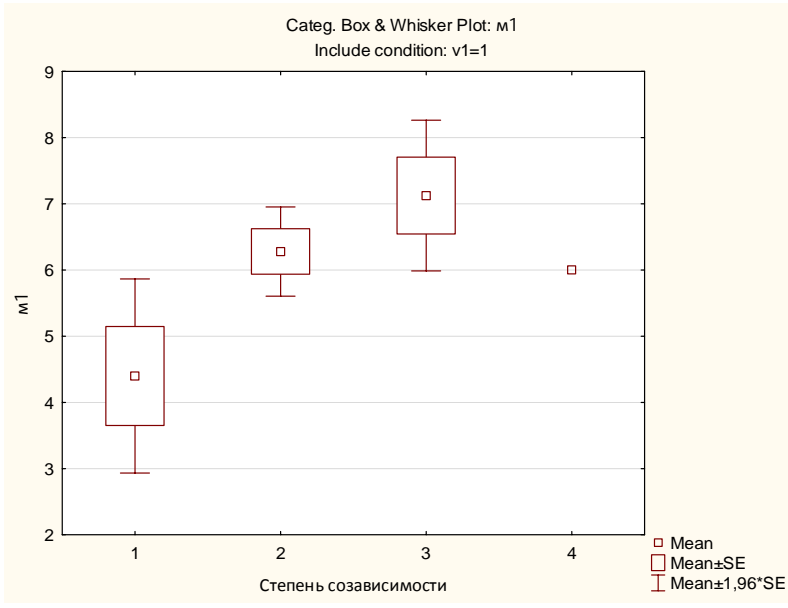

\section{Р и с у н о к 1. Взаимосвязь степеней созависимости} с характеристикой «Планирование»

П р и м е ч а н и е. 1 - Очень высокая степень; 2 - высокая степень; 3 - средняя степень.

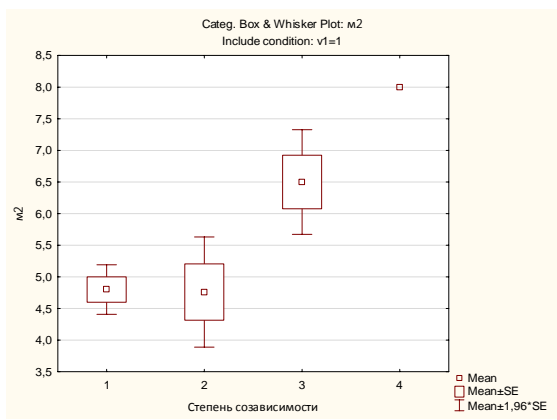

\section{Р и с у н о к 2. Взаимосвязь степеней созависимости} с характеристикой «Моделирование»

Как представлено на рисунке 2, у матерей наркозависимых подростков показатели по шкале «Моделирования» при очень высоком $(4,8 \pm 0,4)$ и высоком уровнях созависимости $(4,7 \pm 2,2)$ не обнаружили различий между собой, но статистически значимо отличаются от показателей при средней степени созависимости $(6,5 \pm 1,2)$, что свидетельствует о сниженной способности к моделированию.

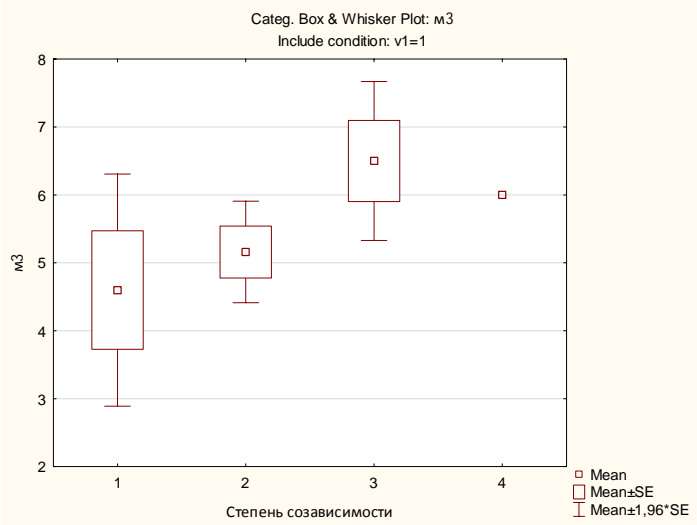

Р и с у н о к 3. Взаимосвязь степеней созависимости с характеристикой «Программирование»
Полученные показатели по шкале «Программирование» демонстрируют (рис. 3) в основной группе у матерей с разной степенью созависимости с очень высоким и высоким уровнями $(4,6 \pm 1,9$ и $5,2 \pm 1,9)$ отсутствие различий между собой и соответствуют нормативным значениям, но статистически значимо отличаются от показателей матерей со средней степенью созависимости $(6,5 \pm 1,7)$.

В свою очередь показатели по шкале «Надежности» $(3,4 \pm 1,7$ и $3,1 \pm 2,4)$ так же не имеют различий между собой и определяются ниже нормативных значений, статистически значимо отличаясь от показателей при средней степени созависимости $(6,9 \pm 1)$.

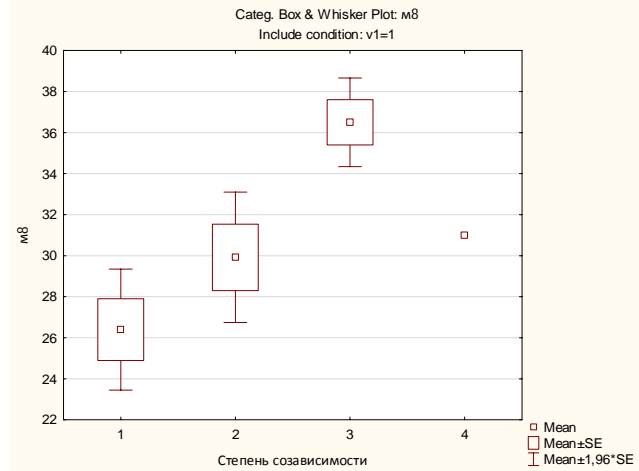

Р и с у н о к 4. Взаимосвязь степеней созависимости с характеристикой «Общий уровень саморегуляции»

Обобщенный показатель, характеризующий процесс саморегуляции в целом по шкале «Общий уровень саморегуляции» с различными уровнями созависимости $(26,4 \pm 3,4 ; 29,9 \pm 8,1$ и $36,5 \pm 3,1)$ имеют статистически значимые различия между собой и находятся в пределах нормы (рис. 4).

Показатели коэффициента вегетативного баланса у матерей с очень высокой степенью созависимости имеют статистически значимые различия со второй и третьей степенями созависимости и свидетельствуют о хронической усталости, повышенной утомляемости. При высокой и средней степенях созависимости выявляется внутренняя готовность к реализации планов. В контрольной группе различия между показателями, характеризующими процессы саморегуляции и степенью созависимости, статистически незначимы.

\section{Обсуждение результатов}

Проведенное исследование особенностей созависимости и психической саморегуляции у матерей наркозависимых подростков (основная группа) и матерей подростков без нарушений психического здоровья (контрольная группа) позволило получить парадоксальные, на первый взгляд, результаты. При этом выявляются следующие закономерности. Наличие высокой степени созависимости отмечается у матерей как основной, так и контрольной группы. Следует обратить внимание, что матери обеих групп находятся в зоне риска, связанной с нарушениями личностного развития и психического здоро- 
вья.

Изучение проявлений саморегуляции показало, что в обеих группах в целом выявлен достаточно высокий общий уровень психической саморегуляции матерей. При этом имеются рассогласования между отдельными ее звеньями. Данные противоречия, видимо, связаны с повышенным уровнем нервно-психической напряженности у матерей обеих групп. Эти данные необходимо проверить в дополнительных исследованиях. Можно утверждать, что развитие осознанной саморегуляции в форме произвольной активности может быть значимым ресурсом, направленным на снижение созависимости и восстановление психического здоровья.

\section{ЗАКЛЮЧЕНИЕ}

Исследование взаимосвязи между степенью созависимости и особенностями саморегуляции свидетельствует о том, что при очень высокой и высокой степенях созависимости такие регуляторноличностные свойства, как оценка результатов, гибкость, способность к саморегуляции в ситуациях повышенной и заниженной мотивации деятельности, а также в условиях высокой и низкой психической напряженности, у матерей основной группы снижены при общем нормативном уровне саморегуляции. Эти показатели, вероятно, компенсируются за счет других проявлений саморегуляции (планирование, моделирование, программирование). Показатели коэффициента вегетативного баланса свидетельствуют о наличии высокого уровня хронической психической истощаемости, которая является фактором риска нарушения психического здоровья.

Достаточно высокий уровень психической саморегуляции у матерей основной группы обусловлен наличием опыта пребывания в длительной стрессогенной ситуации, обусловленной наличием в семье зависимого от ПАВ. Чтобы оставаться состоятельными при выполнении семейных и профессиональных обязанностей, они постоянно находятся в напряженном ритме жизнедеятельности. При этом избыточность усилий способствует накоплению психического перенапряжения и повышенной истощаемости психических процессов. Поэтому программы психопрофилактики при созависимости должны включать направленность на снятие избыточного напряжения и усталости [2, 3, 4, 5, 6, 11, 16].

\section{КОНФЛИКТ ИНТЕРЕСОВ}

Авторы заявляют об отсутствии конфликта интересов в связи с публикацией данной статьи.

\section{ИСТОЧНИК ФИНАНСИРОВАНИЯ}

Авторы заявляют об отсутствии финансирования при проведении исследования.

\section{СООТВЕТСТВИЕ ПРИНЦИПАМ ЭТИКИ}

Работа соответствует этическим стандартам Хельсинской декларации ВМА (протокол заседания этиче- ского комитета НИИ психического здоровья, Томский национальный исследовательский медицинский центр Российской академии наук № 103 от 10.11.2017 г.).

\section{ЛИТЕРАТУРА}

1. Ананьева Г.А. Семья: химическая зависимость и созависимость. М.: Медицина, 2001: 201.

2. Артемцева Н.Г. Феномен созависимости: психологический аспект. М.: РИО МГУДТ, 2012: 222.

3. Бохан Н.А., Катков А.Л., Россинский Ю.А. Ранняя профилактика и неоабилитация больных опийной наркоманией. Павлодар: Изд-во РГКП «РНПЦ МСПН», 2005: 287.

4. Бохан Н.А., Семке В.Я. Коморбидность в наркологии. Томск : Изд-во Том. ун-та, 2009: 510.

5. Бохан Н.А., Стоянова И.Я., Мазурова Л.В. Психология зависимости и созависимости у женщин из аддиктивных семей. Томск: Изд-во «Иван Федоров», 2011: 152.

6. Емельянова Е.В. Кризис в созависимых отношениях. Принципы и алгоритмы консультирования. СПб.: Речь, 2014: 300.

7. Конопкин О.А. Структурно-функциональный и содержательно-психологический аспекты осознанной саморегуляции Психология. Журнал Высшей школь экономики. 2005; 2 (1): 27-42.

8. Мазурова Л.В. Особенности психологической защиты и копинг стратегий у женщин с алкогольной зависимостью и созависимостью (психокоррекционный аспект): дис. ... к.п.н. Томск, 2009: 184.

9. Моросанова В.И., Бондаренко И.Н. Диагностика саморегуляции человека. М.: Когито-Центр, 2015: 304.

10. Москаленко В.Д. Зависимость: семейная болезнь. М.: ПЕР СЭ, 2006: 352

11. Москаленко В.Д. Зависимость: семейная болезнь. Отношения между матерью и сыном. Психотерапия. 2015; 2 (146): 30-37.

12. Назарова И.А., Аболонин А.Ф., Стоянова И.Я. Социальнопсихологические факторы риска формирования делинквентных и аддиктивных форм поведения у юношей и девушек. Сибирский вестник психиатрии и наркологии. 2016; 4 (93). 69-75.

13. Освобождение от созависимости / Перевод с англ. А.Г. Чеславской / Б. Уайнхолд, Дж. Уайнхолд. М: Независимая фирма «Класс», 2006: 224.

14. Петрова О.В., Коханов В.С., Смагина А.А. Созависимость и аутоагрессия в семье больных алкоголизмом Наркология. 2008; 5: 56-66.

15. Семке В.Я., Бохан Н.А., Мандель А.И. Персонологический анализ в контексте систематики аддиктивных состояний. Наркология. 2006; 5, 1 (49): 60-65.

16. Стоянова И.Я., Семке В.Я., Бохан Н.А., Лебедева В.Ф., Казенных Т.В., Мазурова Л.В. Способы психологической коррекции пациентов с невротическими расстройствами и семейной созависимостью: методические рекомендации. Томск, 2011: 23.

17. Чернобровкина Т.В. Социальные функции аддиктивных заболеваний. Наркология. 2008; 4: 50-53.

18. Яцышин С.М. Проявление созависимости в ценностносмысловой сфере матерей при наркотизации ребенка: автореф. дис. ... к.п.н.. СПб., 2003: 23.

19. Liddle H.A. Theory development in a family based therapy for adolescent drug abuse. Journal Clinical Child Psychology. 1999; 28: 521-532.

20. Morosanova V. Self-regulation and Personality. Procedia Social and Behavioral Sciences. 2013; 86: 452-457. URL: http://www.sciencedirect.com/science/journal/18770428/86

Поступила в редакцию 12.11.2017 Утверждена к печати 5.02.2018

Краснятова Юлия Александровна, к.м.н., ассистент кафедры психиатрии, наркологии и психотерапии, заведующая отделением Томского областного наркологического диспансера.

Стоянова Ирина Яковлевна, д.п.н., ведущий научный сотрудник НИИ психического здоровья, профессор кафедры психотерапии и психологического консультирования Томского государственного университета. 
УДК 616.89-008.441.33:159.9.018-055.52-055.2

For citation: Krasnyatova Ju.A., Stoyanova I.Ya. Characteristics of codependence and mental self-control in mothers of adolescents with drug dependence. Siberian Herald of Psychiatry and Addiction Psychiatry. 2018; 1 (98): 42-48. https://doi.org/10.26617/1810-3111-2018-1(98)-42-48

\title{
Characteristics of codependence and mental self-control in mothers of adolescents with drug dependence
}

\author{
Krasnyatova Ju.A. ${ }^{2}$, Stoyanova I.Ya. ${ }^{1,2}$ \\ ${ }^{1}$ Mental Health Research Institute, Tomsk National Research Medical Center, Russian Academy of Sciences \\ Aleutskaya Street 4, 634014, Tomsk, Russian Federation \\ ${ }^{2}$ National Research Tomsk State University \\ Lenin Avenue 36, 634050, Tomsk, Russian Federation
}

\section{ABSTRACT}

In the article features of manifestations of codependence and mental self-control and their interrelationship in mothers of adolescents with drug dependence (the main group) in comparison with mothers of adolescents without mental disturbances are considered. Research methods: the standardized interview, questionnaires of codependence by Weinhold and V.I. Morosanova "Style of self-control of behavior". Results of research. It is established that high degree of codependence in mothers is noted both in the main and control groups $(64.1 \%$ and $53.3 \%)$. The general level of self-control in both groups (30.8 \pm 7.4 and $30.5 \pm 4.9$ accordingly) is high enough. The interrelationship of indicators of individual-style features of self-control and the indicator of codependence in the basic group is traced in all parameters, except "Flexibility" and "Independence". Conclusion. Indicators of factor of vegetative balance give evidence of the presence of high level of chronic mental codependence which is a risk factor of impairment of mental health. Psychopreventive maintenance programs in codependence should include an orientation on removal of superfluous psychological pressure.

\section{Keywords: codependency, mental self-control, family members, adolescents, drug dependence.}

\section{REFERENCES}

1. Ananyeva G.A. Semya: himicheskaya zavisimost i sozavisimost [Family: chemical dependence and codependence]. M.: Meditsina, 2001: 201 (in Russian).

2. Artemtseva N.G. Fenomen sozavisimosti: psihologicheskiy aspect [Phenomenon of codependence: psychological aspect]. Moscow: RIO MGUDT, 2012: 222 (in Russian).

3. Bokhan N.A., Katkov A.L., Rossinsky Yu.A. [Early prevention and neoabilitation of patients with opioid addiction]. Pavlodar: Publishing House of RGKP "RNPC MSPN", 2005. 287 p. (in Russian).

4. Bokhan N.A., Semke V.Ya. [Co-morbidity in Addiction Psychiatry]. Tomsk: Publishing House of Tomsk University, 2009. 510 p. (in Russian).

5. Bokhan N.A., Stoyanova I.Ya., Mazurova L.V. Psihologiya zavi-simosti i sozavisimosti u zhenschin iz addiktivnyih semey [Psychology of dependence and codependence in women from addictive families]. Tomsk: Publishing House "Ivan Fedorov", 2011: 152 (in Russian).

6. Emelyanova E.V. Krizis v sozavisimyih otnosheniyah. Printsipyi i algoritmyi konsultirovaniya [Crisis in codependent relations. Principles and algorithms of counseling]. Sankt-Peterburg: Rech, 2014: 300 (in Russian).

7. Konopkin O.A. Strukturno-funktsionalnyiy i soderzhatelnopsihologicheskiy aspektyi osoznannoy samoregulyatsii [Conscious Self-Control: the Structure/Function and Content Aspects]. Psihologiya. Zhurnal Vyisshey shkolyi ekonomiki - Psychology. Journal of Higher School of Economics. 2005; 2 (1): 27-42 (in Russian).

8. Mazurova L.V. Osobennosti psihologicheskoy zaschityi i koping strategiy u zhenschin s alkogolnoy zavisimostyu i sozavisimostyu (psihokorrektsionnyiy aspekt) хАуфегкуы ща psychological defense and coping-strategies in women with alcohol dependence and codependence (psychocorrective aspect): dis. ... k.p.n. Tomsk, 2009: 184 (in Russian).
9. Morosanova V.I., Bondarenko I.N. Diagnostika samoregulyatsii cheloveka [Diagnosis of self-control of the man]. Moscow: Kogito-Tsentr, 2015: 304 (in Russian).

10. Moskalenko V.D. Zavisimost: semeynaya bolezn [Dependence: family illness]. Moscow: PER SE, 2006: 352 (in Russian).

11. Moskalenko V.D. Zavisimost: semeynaya bolezn. Otnosheniya mezhdu materyu i syinom [Dependence: family illness. Relations between mother and son]. Psihoterapiya - Psychotherapy. 2015; 2 (146): 30-37 (in Russian).

12. Nazarova I.A., Abolonin A.F., Stoyanova I.Ya. Sotsialnopsihologicheskie faktoryi riska formirovaniya delinkventnyih i addiktivnyih form povedeniya u yunoshey i devushek [Socialpsychological risk factors of formation of delinquent and addictive forms of behavior in boys and girls]. Sibirskiy vestnik psihiatrii i narkologii - Siberian Herald of Psychiatry and Addiction Psychiatry. 2016; 4 (93). 69-75 (in Russian).

13. Osvobozhdenie ot sozavisimosti [Release from codependence]. / Perevod s angl. A.G. Che-slavskoy / B. Weinhold, G Weinhold. Moscow: Nezavisimaya firma «Klass», 2006: 224 (in Russian).

14. Petrova O.V., Kohanov V.S., Smagina A.A. Sozavisimost i autoagressiya $\mathrm{v}$ seme bolnyih alkogolizmom [Codependence and autoaggression in the family of alcoholic patients]. Narkologiya. - Narcology. 2008; 5: 56-66 (in Russian).

15. Semke V.Ya., Bokhan N.A., Mandel A.I. Personologicheskiy analiz v kontekste sistematiki addiktivnykh sostoyaniy [Personological analysis in the context of systematics of addictive states]. Narkologiya - Narcology. 2006; 5, 1(49): 60-65 (in Russian).

16. Stoyanova I.Ya., Semke V.Ya., Bokhan N.A., Lebedeva V.F., Kazennykh T.V., Mazurova L.V. Sposobyi psihologicheskoy korrektsii patsientov s nevroticheskimi rasstroystvami i semeynoy sozavisimostyu [Methods of psychological correction of patients with neurotic disorders and family codependence]: guidelines. Tomsk, 2011: 23 (in Russian).

17. Chernobrovkina T.V. Sotsialnyie funktsii addiktivnyih zabolevaniy [Social functions of addictive diseases]. Narkologiya- Narcology. 2008; 4: 50-53 (in Russian). 
18. Yatsyshin S.M. Proyavlenie sozavisimosti v tsennostnosmyislovoy sfere materey pri narkotizatsii rebenka [Manifestation of codependence in value-meaning domain of motheras during narcotization of their children]: avtoref. ... k.p.n.. SanktPeterburg, 2003: 23 (in Russian).

19. Liddle H.A. Theory development in a family based therapy for adolescent drug abuse. Journal Clinical Child Psychology. 1999; 28: 521-532.

Krasnyatova Julia A., candidate of medical sciences, assistant of the Department of Psychiatry, Narcology and Psychotherapy, Head of the Unit of Tomsk Regional Narcological Clinic, Tomsk, Russian Federation.

Stoyanova Irina Ya., Doctor of Psychology, leading researcher of Mental Health Research Institute, Professor of Department of Psychotherapy and Psychological Counseling of Tomsk State University, Tomsk, Russian Federation.

$\triangle$ Krasnyatova Julia A., kulia2012@mail.ru
20. Morosanova V. Self-regulation and Personality. Procedia Social and Behavioral Sciences. 2013; 86: 452-457. URL: http://www.sciencedirect.com/science/journal/18770428/86

Received November 12.2017 Accepted February 5.2017 